Check for updates

Cite this: RSC Adv., 2018, 8, 37817

\title{
Modification of poly(amide-urethane-imide) (PAUI) thin film composite reverse osmosis membrane with nano-silver particles
}

\author{
Li-Fen Liu, (D) *ac Hao Wu, $\uparrow^{\text {ab }}$ Rui-Han Li, $\uparrow^{\text {ac }}$ Chun-yang Yu, (D) d Xue-Ting Zhao (D) *ac \\ and Cong-Jie Gao ${ }^{\text {ac }}$
}

A novel reverse osmosis (RO) composite membrane, poly(amide-urethane-imide@Ag) (PAUI(aAg), was prepared on a polysulfone supporting film through two-step interfacial polymerization. First, in the 1st interfacial polymerization procedure, a new tri-functional crosslinking agent with $-\mathrm{OCOCl}$ and $-\mathrm{COCl}$ groups, 5-choroformyloxyisophaloyl chloride (CFIC), was reacted with 4-methyl-phenylenediamine (MMPD) without curing treatment to obtain the poly(amide-urethane) base membrane with a CFICMMPD precursor separation layer. And then $N, N^{\prime}$-dimethyl-m-phenylenediamine (DMMPD) with nanoAg particle dispersion was introduced onto the base membrane to further construct a CFIC-DMMPD modified ultrathin separation layer via the 2 nd interfacial polymerization. Thus, the PAUI@Ag RO membrane with poly(amide-urethane-imide) bi-layer skin was obtained. The membrane was characterized for the chemical composition of separation layer, the membrane cross-section structure and the membrane surface morphology. Permeation experiment was employed to evaluate the PAUI@Ag membrane performance including salt rejection rate and water flux. The results revealed that the PAUI@Ag membrane composed the highly cross-linked separation layer with entire ridges and valleys, small surface roughness, and well dispersed nano-Ag particles. Upon exposure of the membranes to high concentration of free chlorine solutions, the PAUI@Ag RO membrane showed a slightly less chlorine-resistant property compared with the nascent PAUI RO membrane, but was still superior to the conventional polyamide MPD-TMC RO membrane, meanwhile it processed higher antibiofouling property.

Received 8th June 2018

Accepted 31st October 2018

DOI: $10.1039 / c 8 r a 04906 h$

rsc.li/rsc-advances

\section{Introduction}

Reverse osmosis (RO) technology is increasingly used in seawater desalination, ultrapure water production and wastewater treatment today. ${ }^{\mathbf{1 - 4}}$ The reverse osmosis membrane is the core of RO technology and various polymers have been tried for the production of thin-film composite (TFC) RO membranes. ${ }^{5-13}$ Due to the excellent separation performances including water flux and salt rejection, aromatic polyamide (PA) membranes have been widely accepted as the optimal among such RO membranes. ${ }^{6,14}$ However, oxidation and fouling are currently

\footnotetext{
${ }^{a}$ Center for Membrane and Water Science and Technology, Ocean College, Zhejiang University of Technology, Hangzhou 310014, China. E-mail: lifenliu@zjut.edu.cn; Zhaoxt@zjut.edu.cn

${ }^{b}$ College of Chemical Engineering, Zhejiang University of Technology, Hangzhou 310014, China

${ }^{c}$ Collaborative Innovation Center of Membrane Separation and Water Treatment of Zhejiang Province, Hangzhou 310014, China

${ }^{d}$ School of Chemistry \& Chemical Engineering, State Key Laboratory of Metal Matrix Composites, Shanghai Jiao Tong University, 800 Dongchuan Road, Shanghai, China 200240

$\dagger$ These authors contributed equally.
}

two major obstacles for the aromatic polyamide RO membranes, which limit further application of RO membrane technology. ${ }^{15-20}$ To address these two problems, various approaches have been performed including pretreatment of the RO feed solution, development of new membrane materials, surface modification of commercial RO membranes, ${ }^{21-36}$ optimization of process conditions, and periodic cleaning. ${ }^{37-51}$ Even after long periods of such developments, however, biofouling is still the major reason for performance deterioration of conventional PA membranes including water flux decline and salt rejection reduction..$^{52-56}$

Membrane biofouling is attributed to the biofilm formation that is caused by the adhesion and growth of microbes on the surface of RO membrane during use. ${ }^{57-60}$ At present, the common strategy in preventing membrane biofouling is to add bactericide such as free chlorine into the feed in RO process. However, chlorination cannot completely kill all of microorganisms ${ }^{61}$ especially causes a rapid damage of most conventional PA membrane. ${ }^{62}$ It is thus desirable to find a practicable solution to collaboratively enhance the resistance to bacteria and chlorine of RO membrane during use. 
It is well known that silver has an excellent antibacterial capability and even very low concentrations of silver ions $\left(<0.001 \mathrm{mg} \mathrm{l}^{-1}\right)$ is effective in killing bacteria, ${ }^{63-65}$ so it has been used in many application fields such as burn wound and ulcer healing, ${ }^{\mathbf{6}}$ catheter biofilm inhibiting, and microorganism deactivating etc. Furthermore, there are also various membranes reported by loading silver (silver ion or nanoparticle) onto the membrane surface through different methods to improve the anti-biofouling performance. ${ }^{67-76}$ For example, Dong et al. in situ immobilized silver nanoparticles (AgNPs) onto the commercial polyamide RO membrane (virgin membrane) surface via a two-step surface modification process to improve the membrane's anti-biofouling property ${ }^{68} \mathrm{Chou}$ et al. prepared the silver-loaded cellulose acetate hollow fiber membrane by dissolving $\mathrm{AgNO}_{3}$ in the polymeric casting solution, and the hybrid membrane was evaluated antibacterial activity against both Escherichia coli and Staphylococcus aureus. ${ }^{70}$ Liu et al. also demonstrated that the hybrid PA/Ag nanocomposite membrane possessed dramatic anti-biofouling effect by using layer-by-layer (LbL) assembly method. ${ }^{73,74} \mathrm{Wu}$ and Yang et al. loaded Ag nanoparticles by using polydopamine (PDA) as nano-template on the PA layer and the resultant nanocomposite membranes showed the potential towards long lasting and regenerable anti-biofouling ability in membrane systems. ${ }^{75,76}$

Obviously, loading silver onto the polymeric membrane makes significant contribution to membrane anti-biofouling performance. However, the chlorine resistance property of these Ag-loaded PA composite membranes has scarcely been reported. In reality, chlorine is frequently added to feed water for disinfection and to inhibit biofilm formation and the conventional TFC aromatic polyamide RO membrane is poor resistance to continual exposure to free chlorine, so the modified TFC RO membrane with silver nanoparticles is also expected to be simultaneously less prone to chlorination. It is generally considered that the chlorination of polyamide attributes to the $N$-chlorination by substituting the hydrogen on amide nitrogen, followed by ring-chlorination via Orton rearrangement. ${ }^{77-79}$ Based on this understanding, some approaches for preventing chlorination have been conducted to improve the chlorine resistances of aromatic polyamide RO membrane, such as introducing electron-withdrawing groups in the aromatic ring, increasing steric hindrance of aromatic amide bond with ortho-position methyl group, or directly substituting hydrogen atom for methyl on aromatic amide bond, and surface modification by coating with high chlorine-resistance polymers. ${ }^{80-86}$

In this study, therefore, the new crosslinking agent, 5-choroformyloxyisophaloyl chloride (CFIC) with trifunctional groups (including - $\mathrm{OCOCl}$ and $-\mathrm{COCl}$ ), was proposed to react successively with 4-methyl-phenylenediamine (MMPD) and modified functional diamine $N, N^{\prime}$-dimethyl-m-phenylene diamine (DMMPD) via two-step interfacial polymerization to obtain the chlorine resistant poly(amide-urethane-imide) (PAUI) TFC RO membrane.$^{87-90}$ At the same time, the nanosilver was introduced synchronously in the membrane separation skin layer through the addition in the second aqueous phase of DMMPD. Due to the introduction of nano-Ag and the existence of residual hydrophilic amino group $\left(-\mathrm{NH}_{2}\right)$ instead of carboxylic acid group $(-\mathrm{COOH})$ on membrane surface after the second interfacial polymerization, that the chlorine-resistant and antifouling of the resultant Ag-loaded poly(amide-urethane-imide) membrane (PAUI@Ag) can be enhanced simultaneously. The chemical composition and morphology of the fabricated membrane surface were measured via attenuated total reflectance mode Fourier transform infrared spectroscopy (ATRFTIR), X-ray photoelectron spectroscopy (XPS), scanning electronic microscopy (SEM) and atomic force microscopy (AFM). Exposure of the membranes to high concentration of free chlorine solutions was carried out to evaluate the chlorineresistant property of the fabricated RO membrane. A preliminary investigation of antifouling performance of the silverloaded TFN RO membrane was also performed.

\section{Materials and methods}

\subsection{Materials and chemicals}

5-Choroformyloxyisophaloyl chloride (CFIC, Fig. 1) was synthesized via triphosgene (BTC) method in the presence of composite catalyst imidazole-pyridine, ${ }^{\mathbf{9 1}}$ and $N, N^{\prime}$-dimethyl-mphenylenediamine (DMMPD, Fig. 1) was prepared by the reduction method with composite $\mathrm{NaBH}_{4}-\mathrm{I}_{2} \cdot{ }^{{ }^{22}} m$ Phenylenediamine-4-methyl (MMPD, purity > 99.5\%) was purchased from J\&K Scientific Ltd. Nanosilver colloid solution (nano-Ag, 10-30 nm) was provided by the Shanghai Weilang Nanomaterial Co. Ltd. All other chemicals are analytic purity grade unless otherwise specified and used as received without further purification. Deionized (DI) water with conductivity less than $5 \mu \mathrm{S} \mathrm{cm}{ }^{-1}$ was produced by a two-stage reverse osmosis system (Scheme 1).

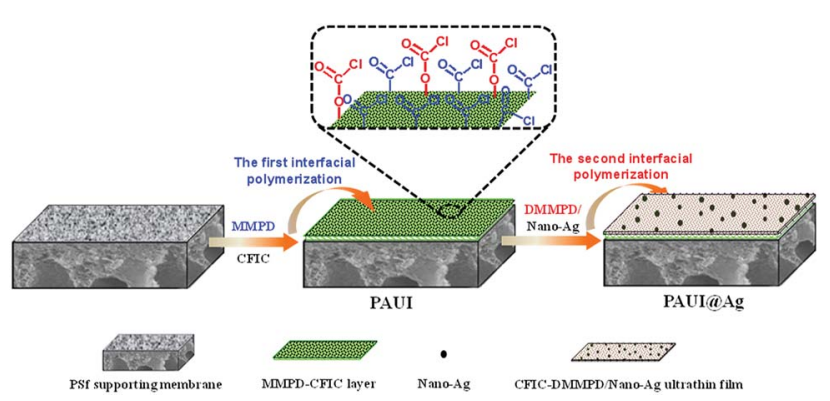

Fig. 1 Schematic illustration of fabrication process of PAUI@Ag RO membrane via two-step interfacial polymerization.

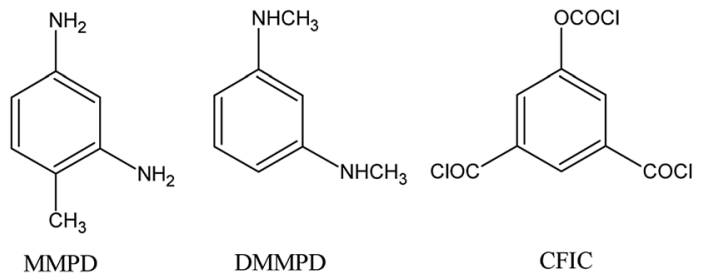

Scheme 1 Chemical structure of the used functional monomers. 


\subsection{Fabrication of RO membranes}

2.2.1 Conventional aromatic polyamide membrane. The polysulfone (PSF) substrates with $M_{\mathrm{w}}$ of 200000 Da were supplied by the Center of Water Treatment Technology, Hangzhou, China. The conventional aromatic polyamide RO membrane (MPD-TMC) was fabricated by the conventional interfacial polymerization method. First, the PSF substrate was clamped between two Teflon frames with the inner length and width of $20 \mathrm{~cm}$ and $15 \mathrm{~cm}$, respectively. The top surface of PSF substrate was immersed into the aqueous solution for $2 \mathrm{~min}$ which was composed of $2.0 \mathrm{wt} \%$ MPD, triethyl amine (TEA, $3.0 \mathrm{wt} \%$ ), sodium dodecyl sulfate (SDS, $0.15 \mathrm{wt} \%$ ) and (+)-10-camphor sulfonic acid (CSA, $4.0 \mathrm{wt} \%)$. The excess solution was then drained, and the membrane was air-dried at ambient temperature until no visible liquid drops were on the surface. Subsequently, the organic solution containing $0.15 \mathrm{wt} \%$ TMC was reacted with residual MPD on the surface of PSF substrate for $60 \mathrm{~s}$. The resultant membrane was finally heated at $60{ }^{\circ} \mathrm{C}$ in the air dryer to further polymerization. The obtained MPD-TMC membrane was washed by DI water and stored in $1.0 \mathrm{wt} \% \mathrm{NaHSO}_{3}$ solution for further modification.

2.2.2 Poly(amide-urethane-imide) membranes including PAUI and PAUI@Ag. Both of the poly(amide-urethane-imide) TFC RO membranes including PAUI and PAUI@Ag were prepared through two-step interfacial polymerization technology in a clean room (Fig. 1), ${ }^{93}$ and the PAUI@Ag membrane was based on the modification of PAUI nascent membrane with nano-Ag particles by introduction in the second aqueous phase solution.

The first aqueous phase solution was prepared with $2.0 \mathrm{wt} \%$ MMPD, $3.0 \mathrm{wt} \%$ TEA, $0.15 \mathrm{wt} \%$ SDS and $4.0 \mathrm{wt} \% \mathrm{CSA}$, and the second aqueous solution was composed of $1.0 \mathrm{wt} \%$ DMMPD, $3.0 \mathrm{wt} \%$ TEA, $0.15 \mathrm{wt} \%$ SDS, $4.0 \mathrm{wt} \% \mathrm{CSA}$ and $100 \mathrm{mg} \mathrm{l^{-1 }}$ nanosilver particle (particle diameter: $10-30 \mathrm{~nm}$ ). It should be noticed that the second aqueous phase for fabricating PAUI@Ag membrane contained nanosilver. Firstly, the first aqueous phase solution was poured into the top surface of the PS support to soak for 2 min. After removing the excess solution from the dip-coated surface and air-drying at ambient temperature, the organic phase solution of CFIC ( $0.15 \mathrm{wt} \%)$ in hexane was then poured rapidly into the MMPD-saturated surface for the first polymerization reaction. After polymerization of $40 \mathrm{~s}$, the excess organic solution was drained from the surface of the obtained nascent poly(amide-urethane) base membrane and air-dried adequately at ambient temperature until no remaining liquids. Subsequently, the second aqueous phase solution was fast poured into the top surface of the poly(amide-urethane) base membrane for the second interfacial polymerization (60 s) of DMMPD and the residual unreacted CFIC or functional groups (-COCl and/or -OCOCl). After removing the excess second aqueous solution, the membrane with frame was heated to $100{ }^{\circ} \mathrm{C}(8 \mathrm{~min})$ in the air dryer for further polymerization, leading to the formation of skin bi-layer including poly(amideurethane) CFIC-MMPD precursor separation layer and ultrathin polyimide CFIC-DMMPD modified separation layer. Finally, the resultant PAUI and PAUI@Ag membranes were washed in DI water and stored in $\mathrm{NaHSO}_{3}$ solution (1.0 wt\%).

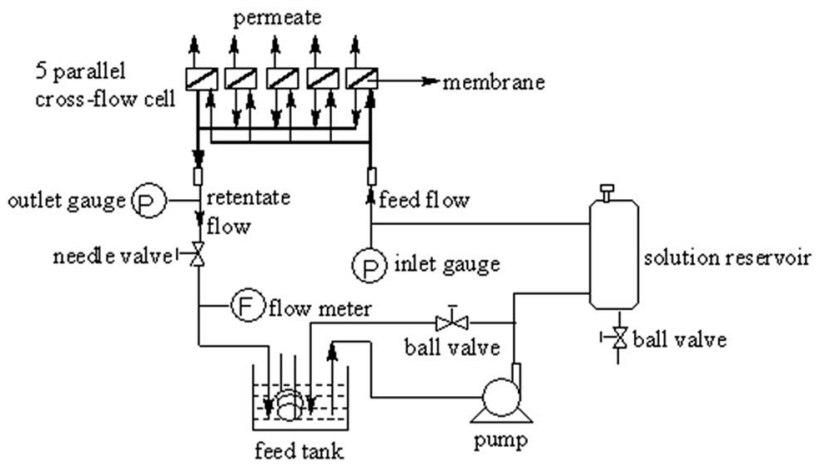

Fig. 2 Device for the permeation tests.

\subsection{Membrane separation performance test}

Water flux and salt-rejection performance tests were performed in duplicates for at least 3 times using a homemade stainless steel cross-flow membrane filtration unit (Fig. 2). The filtration unit contained 5 parallel test units, and the averaged measurements were reported. The membrane samples were picked carefully under a fluorescent lamp to eliminate samples with deficits before testing. Membrane coupons with a diameter of $40 \mathrm{~mm}$ (effective area: $12 \mathrm{~cm}^{2}$ ) were soaked in DI water (room temperature, $>30 \mathrm{~min}$ ) prior to loading to the test unit. The membrane was equilibrated with DI water $\left(1.55 \mathrm{MPa}, 25^{\circ} \mathrm{C}, 2 \mathrm{~h}\right)$ before the permeation tests to ensure stable membrane.

When flux was maintained steady for at least 30 minutes, an appropriate volume of $\mathrm{NaCl}$ solution was added to provide desired salt concentration. The running unit was also allowed to equilibrate until a satisfactory steady-state flux was again reached. Permeate, retentate, and feed samples were drawn, and salt rejection rate $(R, \%)$ and water flux $\left(J_{\mathrm{v}}, \mathrm{L} \mathrm{m}^{-2} \mathrm{~h}^{-1}\right)$ were calculated respectively.

$$
R=1-\frac{C_{\mathrm{p}}}{C_{\mathrm{f}}}
$$

where $R$ is the percent solute rejection, and $C_{\mathrm{p}}$ and $C_{\mathrm{f}}\left(\mathrm{g} \mathrm{l}^{-1}\right)$ are the concentrations of solute in the permeate and feed, respectively. The salt concentration in the feed and permeate was calculated according to the electrical conductivity of the corresponding salt solution using an electrical conductivity (DDS11A, Hangzhou Dongxing Instrument Co., China).

$$
J=\frac{V}{A \times \Delta t}
$$

where $A\left(\mathrm{~m}^{2}\right)$ is the effective area of the membrane for permeation, and $V(\mathrm{l})$ is the volume of permeated water over a time interval $\Delta t(\mathrm{~h})$.

\subsection{Membrane active chlorine exposure experiment}

It has been reported that the short-time exposure of membrane to high concentration of active chlorine is equivalent to that of long-time exposure to low concentration of active chlorine. ${ }^{\mathbf{9 4 , 9 5}}$ In this study, therefore, membrane chlorination experiments were carried out by soaking in high concentration of active chlorine solutions at constant $\mathrm{pH} 8.0$ for a short time to evaluate the membrane chlorine-tolerant property. The membranes were 
exposed respectively to $8000 \mathrm{mg} \mathrm{l}^{-1}$ chlorine solutions for $1 \mathrm{~h}$. The soaking tests were performed in Pyrex glass bottles covered with PTFE (polytetrafluoroethylene) caps, and the contents were mixed on a shaker. Exact concentrations were determined by titration with a sodium thiosulfate standard. After that, the separation performances of the membranes were tested after being thoroughly rinsed with deionized water. Data in this paper are normalized to make the comparison more straightforward.

\subsection{Membrane fouling test}

In this study, the membrane fouling test was carried out via dynamic soaking in the original Westlake water with bacteria (Table 1) for a long time (not less than 7 days) with vigorous stirring to evaluate the membrane resistance to biofouling. After soaking, the membrane samples were observed via SEM whether the bacteria adhere to the membrane surface after being thoroughly rinsed with deionized water and dried under vacuum. Meanwhile, the separation performances of the soaked membranes were also measured.

\subsection{Characterization of membrane}

ATR-FTIR (Nicolet560 FTIR, US Nicolet Corp., USA) spectra was employed to analysis the functional groups and bonds of the near-surface region of the membrane skin layer. Surface chemical characterization was performed using XPS (PHI 5000C ESCA System, USA), and the obtained data further were analyzed through PHI ACCESS ESCA-V6.0 F software package. SEM of the fractured surface and cross section for the TFC RO membrane with polysulfone supporting film was conducted on JSM-5610LV. The surface morphology was determined by AFM (Park Instrument Auto Probe CT) combined with SEM (S-4700, Hitachi Ltd., Japan). The existence and morphology of nanosilver particles in the membrane separation layer was observed by TEM (Tecnai G2 F30 S-Twin, 300 kV, Philips FEI Co., Holand). All membrane samples were removed from storage in $\mathrm{NaHSO}_{3}$ solution and soaked in DI water (room temperature, $>30 \mathrm{~min}$ ), then rinsed in DI water for 2-3 times to remove any remaining $\mathrm{NaHSO}_{3}$, and lastly dried under vacuum before measurements.

Table 1 Composition of water from the Westlake

\begin{tabular}{ll}
\hline Species & Quantity \\
\hline $\mathrm{K}^{+}$and $\mathrm{Na}^{+}, \mathrm{mg} \mathrm{l}^{-1}$ & 11.96 \\
$\mathrm{Ca}^{2+}, \mathrm{mg} \mathrm{l}^{-1}$ & 30.78 \\
$\mathrm{Mg}^{2+}, \mathrm{mg} \mathrm{l}^{-1}$ & 2.330 \\
$\mathrm{Fe}_{(\mathrm{Total})}, \mathrm{mg} \mathrm{l}^{-1}$ & 0.03 \\
$\mathrm{HCO}_{3}^{-}, \mathrm{mg} \mathrm{l}^{-1}$ & 79.64 \\
$\mathrm{Cl}^{-}, \mathrm{mg} \mathrm{l}^{-1}$ & 20.00 \\
$\mathrm{SO}_{4}{ }^{2-}, \mathrm{mg} \mathrm{l}^{-1}$ & 18.43 \\
$\mathrm{HA}^{-1} \mathrm{mg} \mathrm{l}^{-1}$ & $<5$ \\
$\mathrm{NO}_{2}{ }^{-}, \mathrm{mg} \mathrm{l}^{-1}$ & 10.78 \\
$\mathrm{SiO}_{2}, \mathrm{mg} \mathrm{l} l^{-1}$ & 8.30 \\
$\mathrm{Turbidity}_{\mathrm{NTU}}$ & 20.5 \\
$\mathrm{COD}_{(\mathrm{Mn})}, \mathrm{mg} \mathrm{l}^{-1}$ & 7.12 \\
$\mathrm{Bacteria}^{-1} \mathrm{CFU} \mathrm{ml}$ & \\
& 757
\end{tabular}

\section{Results and discussion}

The poly(amide-urethane) membrane was fabricated based on MMPD and CFIC monomers via conventional interfacial polymerization method without curing treatment. Nano-Ag particles were successfully applied to modify the poly(amide-urethane) membrane along with DMMPD monomers through two-step interfacial polymerization method for anti-biofouling purpose. Thus, the PAUI@Ag RO membrane was obtained without scarifying the chlorine-tolerant property. For comparison, the PAUI RO membranes were also fabricated without adding nano-Ag particles. Several results were obtained as below.

\subsection{Chemical composition of the separation layer}

The ATR-FTIR was employed to analyze the chemical composition of the separation layer of TFC reverse osmosis membrane and the ATR-FTIR spectra of PAUI and PAUI@Ag RO membranes were presented in Fig. 3. The $\nu \mathrm{C}=\mathrm{O}$ peak at $1724 \mathrm{~cm}^{-1}$ is an evidence of formation of urethane bond $(-\mathrm{OCONH}-)$ and/or the methylurethane bond $\left(-\mathrm{OCON}\left(\mathrm{CH}_{3}\right)^{-}\right)$in the separation layer. The amide $\mathrm{I}\left(\nu \mathrm{C}=\mathrm{O}, 1639 \mathrm{~cm}^{-1}\right), \mathrm{II}(\delta \mathrm{NH}$, $\left.1531 \mathrm{~cm}^{-1}\right)$ and III $(\nu \mathrm{C}-\mathrm{N}, 1242)$ peaks of the separation layer respectively are clearly identified as evidences of existing of functional acylamide bond (-CONH-) and/or the methylacrylamide bond $\left(-\mathrm{CON}\left(\mathrm{CH}_{3}\right)-\right)$. The peaks are located at 1589 and $1488 \mathrm{~cm}^{-1}$ as expected for the benzene ring vibration in the body frame of aromatic polymer. The double peaks at 1150 and $1100 \mathrm{~cm}^{-1}$ as expected for the $\mathrm{C}-\mathrm{O}$ stretching vibration from urethane and/or methylurethane bond. At the same time, it is clearly seen that the PAUI@Ag RO membrane exhibited sharper and larger characteristic peaks at 1531 and $1242 \mathrm{~cm}^{-1}$ for amide bond and at 1150 and $1100 \mathrm{~cm}^{-1}$ for urethane bond, indicating the higher contents of amide and urethane bond in the separation layer. The higher contents of amide and urethane bonds were believed to be attributed to the higher cross-linking degree of the membrane separation layer.

The XPS was further employed to analyze the chemical composition of the top-most separation layer of TFC reverse osmosis membrane with the sampling depth about 10-90 A.

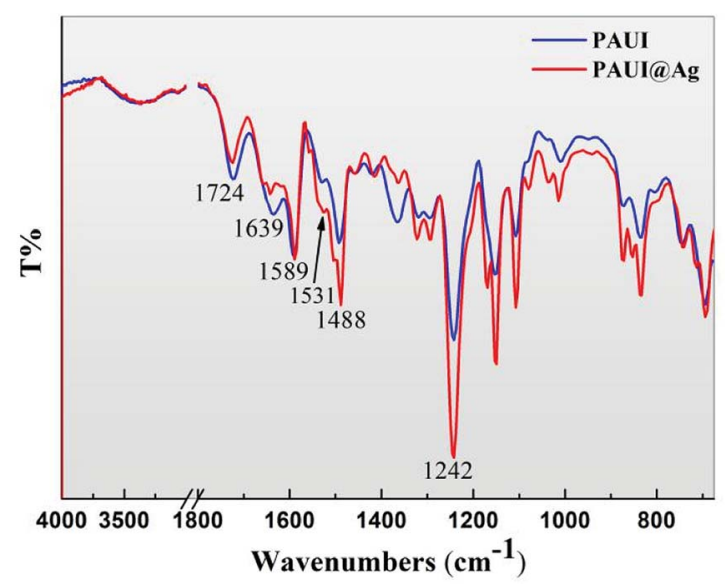

Fig. 3 ATR-FTIR spectrum of PAUI and PAUI@Ag RO membrane, respectively. 


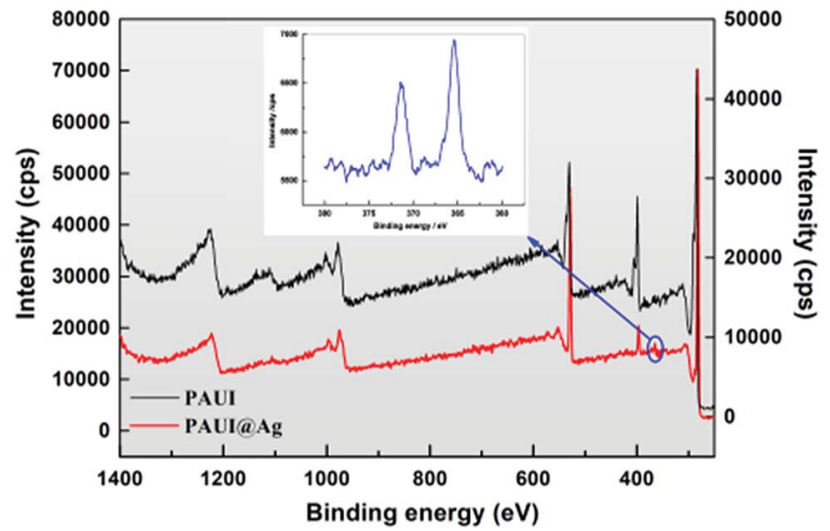

Fig. 4 XPS spectrum of PAUI and PAUI@Ag RO membranes.

Table 2 Elemental composition of the PAUI and PAUI@Ag RO membranes

\begin{tabular}{lcccccc}
\hline Item & $\mathrm{C} \%$ & $\mathrm{O} \%$ & $\mathrm{~N} \%$ & $\mathrm{C} / \mathrm{N}$ & $\mathrm{C} / \mathrm{O}$ & $\mathrm{O} / \mathrm{N}$ \\
\hline PAUI & 73.14 & 14.94 & 11.92 & 6.14 & 4.9 & 1.25 \\
PAUI@Ag & 74.88 & 15.04 & 13.08 & 5.72 & 4.98 & 1.15
\end{tabular}

The quantitative elemental compositions of the top-most layer of the PAUI and PAUI@Ag RO membranes were calculated from the spectrum (Fig. 4) and summarized in Table 1. The XPS wide scans spectra of both nascent PAUI and PAUI@Ag RO membranes revealed three characteristic signals of $\mathrm{C}, \mathrm{N}$, and $\mathrm{O}$ elements at 282397 , and $528 \mathrm{eV}$, respectively, which was consistent with the chemical compositions of the separation layer of membranes. Different with spectra of the nascent PAUI RO membrane, the spectra of PAUI@Ag RO membrane showed the appearance of new binding energy peak of $\mathrm{Ag}$ at $368 \mathrm{eV}$, and the high-resolution XPS spectra exhibited two contributions from $\mathrm{Ag} 3 \mathrm{~d} 5 / 2$ and $\mathrm{Ag} 3 \mathrm{~d} 3 / 2$ at around $373 \mathrm{eV}$ and $366 \mathrm{eV}$, respectively. Both of the peaks were attributed to the AgO species, indicating the presence of Ag NPs on the PAUI@Ag RO membrane surface. ${ }^{96}$

The separation layers of the PAUI and PAUI@Ag membranes derived from interfacial polymerization is typically highly crosslinked to ensure the high salt rejection. In reality, the reaction scheme could vary between full cross-linked routes, full linear routes and their combination. The lower $\mathrm{C} / \mathrm{N}$ and $\mathrm{O} / \mathrm{N}$ ratio of separation layers usually predict higher cross-linking degree. The relative atomic concentration of $\mathrm{C}, \mathrm{O}$, and $\mathrm{N}$, as well as the corresponding $\mathrm{C} / \mathrm{N}, \mathrm{C} / \mathrm{O}$, and $\mathrm{O} / \mathrm{N}$ ratios were summarized in Table 2. The N\% content of the PAUI@Ag RO membrane was increased upon nano-Ag particle loading compared with that of the nascent PAUI RO membrane. Accordingly, the corresponding $\mathrm{C} / \mathrm{N}$ and $\mathrm{O} / \mathrm{N}$ ratios were decreased, indicating the enhanced cross-linking degree of membrane separation layer. The XPS analysis was accordant with the result of ATR-FTIR.

\subsection{Physical morphology of the separation layer}

The combination of FESEM, AFM and TEM was employed to observe the physical morphology of separation layers of the
PAUI and PAUI@Ag membranes. The surface and cross-section morphologies of PAUI and PAUI@Ag RO membranes are shown in Fig. 5 and 6. The surface of PAUI RO membranes exhibited the typical ridge-and-valley structure, thus leading to a relatively high surface roughness. Upon Nano-Ag loading, the surface of PAUI@Ag RO membranes showed much smaller ridge-andvalley structure, and thus the surface roughness of PAUI@Ag RO membranes is obviously decreased. This phenomenon could be ascribed to the fact that the nanoscale size of nano-Ag particles and their affinity to the multiple functional groups of PAUI network could confine the further growing of large ridgeand-valley structure, leading to a significantly reduced surface roughness. This tendency of the ridge-and-valley morphology affected by mixing with nanoscale particles was also reported by other work. ${ }^{97}$ The cross-section of both PAUI and PAUI@Ag RO membranes exhibited the typical thin-film composite structure with thickness of the separation layer about $200-300 \mathrm{~nm}$. With the introduction of nano- $\mathrm{Ag}$ particles, the thickness of the selective layer increases from $231 \pm 31 \mathrm{~nm}$ for nascent PAUI RO

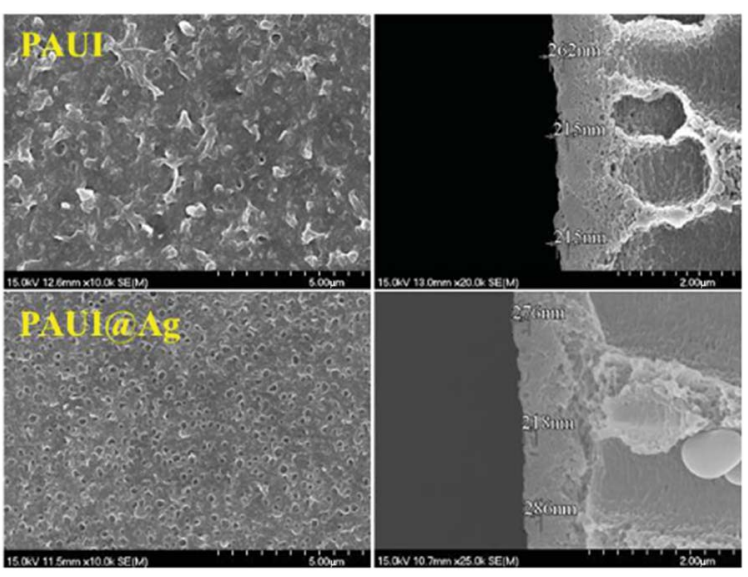

Fig. 5 SEM images of PAUI and PAUI@Ag RO membranes.
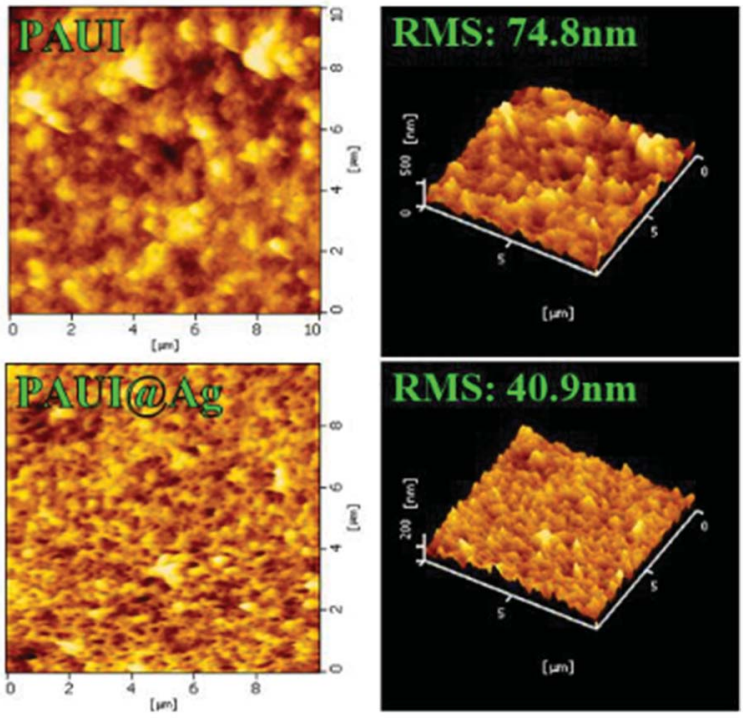

Fig. 6 AFM images of the PAUI and PAUI@Ag RO membranes. 


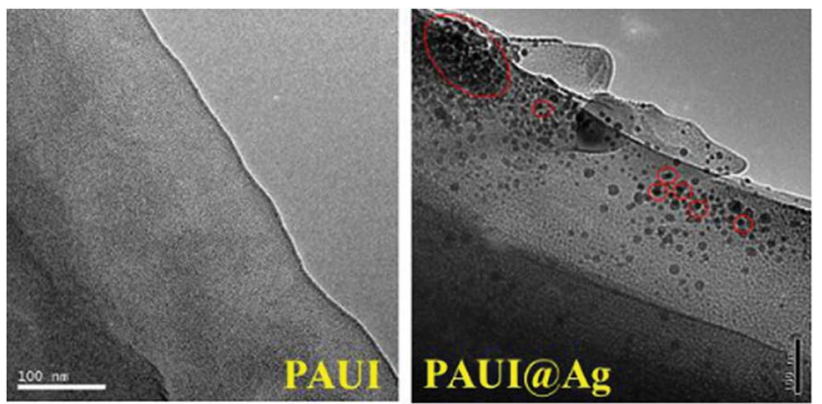

Fig. 7 TEM images of poly(amide-urethane-imide) membrane without and with silver-loaded.

membrane to $260 \pm 42 \mathrm{~nm}$ for PAUI@Ag RO membranes. The cross-section TEM images in Fig. 7 are also used to further confirm the encapsulation of the nano-Ag particles into the separation layer of PAUI@Ag RO membranes. The presence of nano-Ag particles within the separation layer is evident and the embedded nano-Ag particles were mostly enriched at the nearsurface region, indicating the successful incorporation of nanoAg particles into the CFIC-DMMPD modified separation layer of PAUI@Ag RO membranes.

\subsection{Reverse osmosis performance of the membranes}

The separation performance of the PAUI and PAUI@Ag RO membranes was evaluated under the test condition of $2000 \mathrm{ppm}$ $\mathrm{NaCl}$ solution, $1.55 \mathrm{MPa}$ and $25{ }^{\circ} \mathrm{C}$. The desalination rate and water flux were the average values respectively tested from three different samples at the same time presented in Fig. 8. As compared with the nascent PAUI RO membrane, the water flux of the PAUI@Ag RO membrane with nano-Ag particle loading was decreased to some extent. The decrease of water flux could due to the fact that the higher cross-linking degree and thickness of the separation layer of PAUI@Ag RO membrane increased hydraulic resistance of separation layer and thus affected the pressure drop of membrane. Meanwhile the salt rejections of the PAUI@Ag RO membrane was increased upon nano-Ag particle loading compared with that of the nascent PAUI RO membrane. It is no doubt that the high cross-linking degree of the separation layer of PAUI@Ag RO membrane ensured the high rejection ability. Obviously, this result indicated that the introduction of nano-Ag particle did not cause defects in the separation layer of RO membrane. It was purposed that the affinity of nano-Ag particles to the multiple functional group of separation layer inhibited the formation of membrane defects and resulted in a denser PAUI network in the separation layer of RO membrane.

\subsection{Chlorine-tolerant property of the membranes}

The chlorine-tolerant property of the PAUI and PAUI@Ag RO membranes was evaluated by comparing the water flux and salt rejection of membranes before and after exposing in $8000 \mathrm{mg} \mathrm{l}^{-1}$ chlorine solutions, under the test condition of $1.55 \mathrm{MPa}, 2000 \mathrm{ppm} \mathrm{NaCl}, 25.0 \pm 2.0^{\circ} \mathrm{C}$. Fig. 9 represented the change in the water fluxes and salt rejections of PAUI and

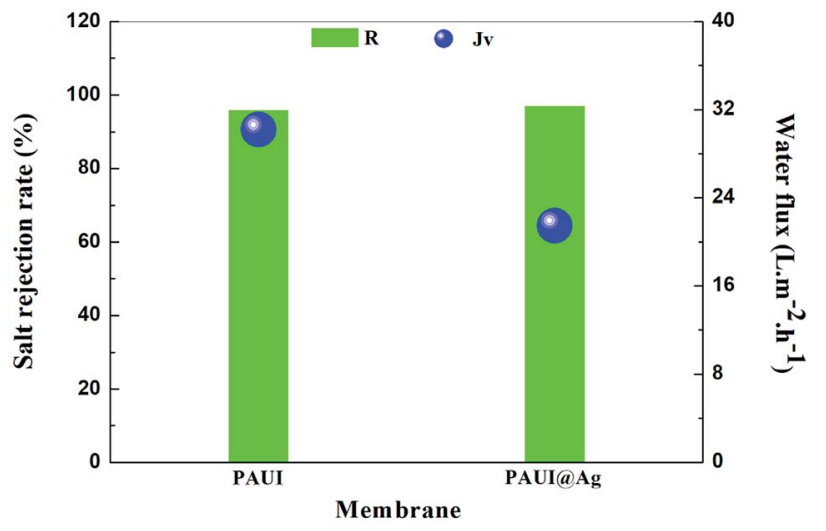

Fig. 8 Separation performance of PAUI and PAUI@Ag RO membranes. Testing conditions: $1.55 \mathrm{MPa}, 2000 \mathrm{ppm} \mathrm{NaCl}, 25.0 \pm 2.0^{\circ} \mathrm{C}$.

PAUI@Ag RO membranes before and after chlorination as compared to that of the conventional aromatic polyamide RO membrane MPD-TMC. It can be seen that the salt rejection rate of MPD-TMC was greatly decreased after exposing in $8000 \mathrm{mg}$ $1^{-1}$ chlorine solutions and correspondingly its water flux was dramatically increased. For PAUI RO membrane, there presented only a slight performance decline with lower salt rejection and higher water flux. The chlorine resistance of the PAUI RO membrane can be attributed to the unique chemical structure of CFIC-DMMPD modified separation layer. For conventional aromatic polyamide, the Orton-rearrangement and subsequent $N$-chlorination and ring-chlorination reactions could disrupt the formation of intermolecular hydrogen bonds and destroy the symmetry of polyamide network, leading to the severe conformational deformations of polyamide chains and the remarkable performance decline. ${ }^{77-79}$ The CFIC-DMMPD modified separation layer contains a relative large amount of polyimide bonds with $N$-position substituted methyl group. These characters improved the chlorine resistance of PAUI RO membrane though increasing the steric hindrance of active chlorine attacking and decreasing the of aromatic amide bond. ${ }^{80,81,93}$ For PAUI@Ag RO membrane, the salt rejection

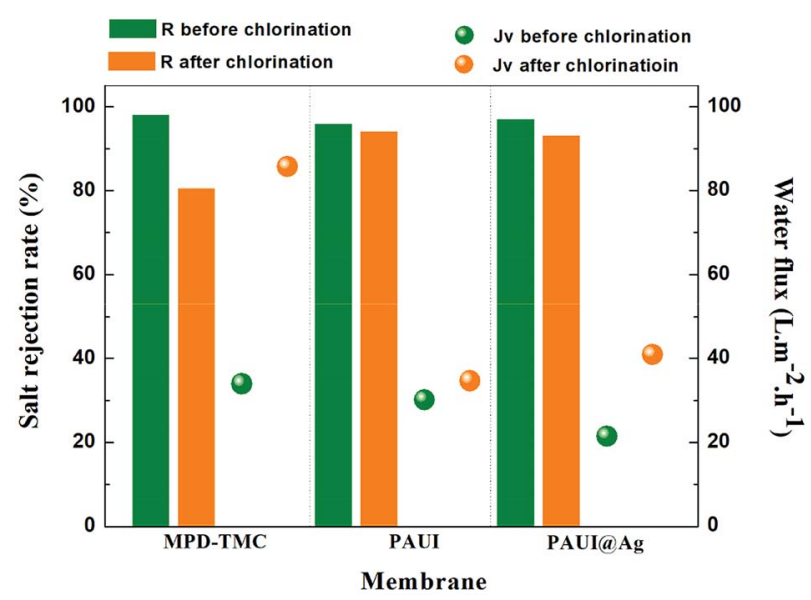

Fig. 9 Chlorine-tolerant property of the PAUI and PAUI@Ag RO membranes compared to conventional polyamide membrane MPDTMC. Testing conditions: $1.55 \mathrm{MPa}, 2000 \mathrm{ppm} \mathrm{NaCl}, 25.0 \pm 2.0^{\circ} \mathrm{C}$. 


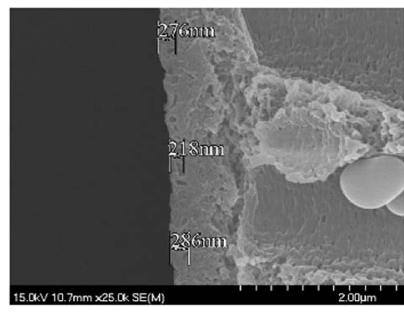

(a)

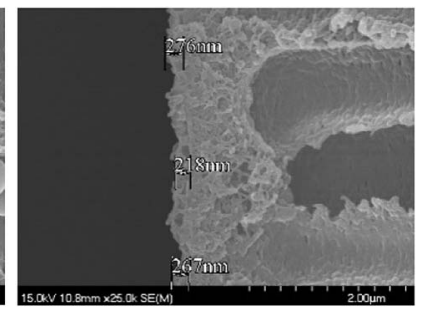

(b)
Fig. 10 TEM images of silver-loaded poly(amide-urethane-imide) membrane before and after chlorination. (a) Before chlorination; (b) after chlorination.

slightly dropped from $95 \%$ to $90 \%$ and the water flux increased from 22 to $40 \mathrm{~L} \mathrm{~m}^{-2} \mathrm{~h}^{-1}$ after chlorination, so the modified PAUI@Ag membrane had relatively slightly weaker chlorineresistant property than that of the vacant PAUI membrane but still superior to MPD-TMC membrane. Considering the robust chlorine-tolerant property of CFIC-DMMPD modified separation layer, the decline performance could be attributed to the oxidation of nano-Ag particles to $\mathrm{AgCl}$ species under high concentration of active chlorine. It was suggested that the oxidation of nano-Ag particles would change the microstructure of the membrane separation layer and generated some micro defects within the PAUI network (Fig. 10(b)), but did not significantly alter the chemical structure and the degree of cross-linking as demonstrated by. ${ }^{93}$ Obviously, the two poly(amide-urethane-imide) membranes including PAUI and PAUI@Ag have favourable chlorine-resistant property than conventional polyamide MPD-TMC membrane.

\subsection{Antifouling property of the membranes}

Fouling study was evaluated for the membrane after fouled by the real lake water. The permeate performances of the fouled PAUI and PAUI@Ag RO membranes were tested as compared to that of the conventional MPD-TMC membrane. Table 3 represented the change in the flux decline rate of RO membranes after dynamic soaking in the Westlake water for a long time. The decline in water flux was observed due to the formation of fouling on the membrane surfaces (Fig. 10). The presence of microorganism in the Westlake water resulted in a significant decline in flux of the MPD-TMC and PAUI membranes. In contrast, the PAUI@Ag RO membrane showed only 3.3\% of flux decline, implying the excellent anti-biofouling property of

Table 3 Flux stability of membranes after be immersed in the Westlake water

\begin{tabular}{llll}
\hline Membrane & $\begin{array}{l}\text { Flux before be } \\
\text { fouled }\left(\mathrm{L} \mathrm{m}^{-2} \mathrm{~h}^{-1}\right)\end{array}$ & $\begin{array}{l}\text { Flux after be } \\
\text { fouled }\left(\mathrm{L} \mathrm{m}^{-2} \mathrm{~h}^{-1}\right)\end{array}$ & $\begin{array}{l}\text { Flux decline } \\
\text { rate }^{a}(\%)\end{array}$ \\
\hline MPD-TMC & 34 & 26.5 & 22.2 \\
PAUI & 30.2 & 27.3 & 9.7 \\
PAUI@Ag & 21.5 & 20.8 & 3.3
\end{tabular}

a Test conditions: (1) the fouling experiment was carried out for 6 hours; (2) the flux decline rate was calculated from the equation of (1 $\left.-J_{\mathrm{W}} / J_{\mathrm{W}_{0}}\right) \times 100 \%$.

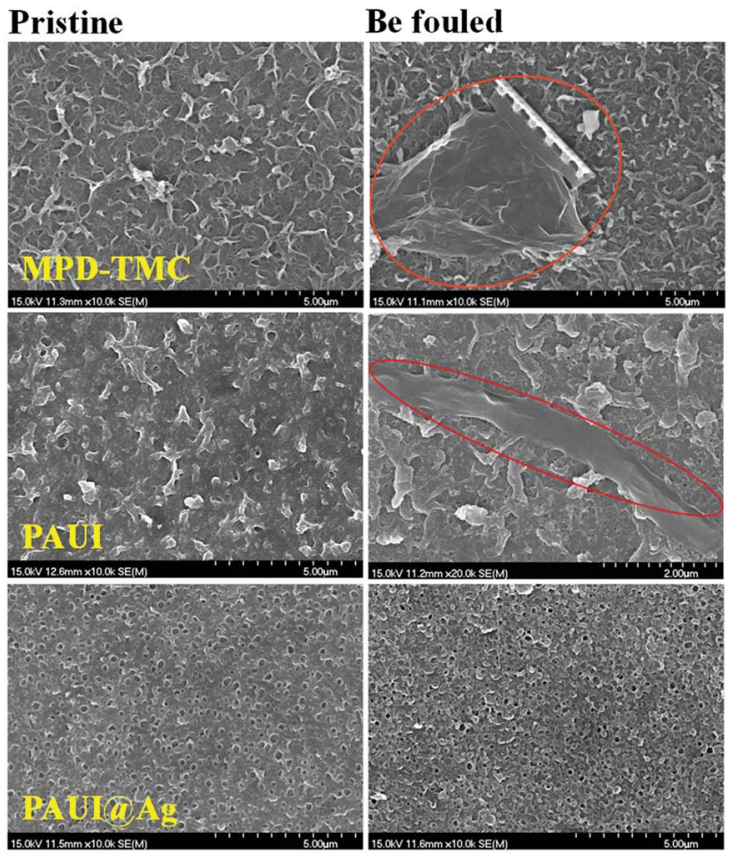

Fig. 11 SEM images of membranes before and after being fouled by dipping in the Westlake water for 7 days.

PAUI@Ag RO membrane. Biofilm formed on the fouled membranes was further investigated using SEM. Fig. 11 showed the change in the surface morphologies of fouled RO membranes. For MPD-TMC and PAUI RO membranes, there existed visible bacterial metabolites on membrane surface, indicating severe biofouling. Meanwhile, the surface of the PAUI@Ag RO membrane seems clean after biofouling with no obvious change in surface morphology. On one hand, the smoother surface of PAUI@Ag RO membrane could limit the adsorption tendency of bacterial metabolites or extracellular polymeric substances on the surface and resist the formation of biofilm. ${ }^{98}$ On the other hand, the antibacterial activity of nanoAg particles could inhibit the bacterial reproduction and proliferation on the membrane surface and avoid the gradual formation of mature biofilm. ${ }^{99}$

\section{Conclusions}

In conclusion, a novel PAUI@Ag reverse osmosis composite membrane containing bi-layer of the poly(amide-urethane) CFIC-MMPD precursor separation layer and a antifouling and chlorine-resistant functional layer of ultrathin polyimide CFICDMMPD film modified with nano-Ag particle dispersion was prepared through two-step interfacial polymerization. Characterizations were used to exhibit the chemical composition and physical morphology of the PAUI@Ag RO membrane. The RO performance of the PAUI@Ag RO membrane evaluated that the introduction of nano-Ag particles endowed membrane with higher rejection abilities and relatively lower permeability. The change of RO performance of the PAUI@Ag RO membrane after chlorine exposure evaluated that the PAUI@Ag RO membrane could still maintain high level of rejection abilities without 
obvious sacrifice on the membrane performance. Furthermore, the PAUI@Ag RO membrane also exhibited better antifouling ability in natural water system. Therefore, the PAUI@Ag RO membrane would provide chlorine-resistant and antibiofouling candidate for practical applications.

\section{Conflicts of interest}

There are no conflicts to declare.

\section{Acknowledgements}

The current study was supported by the National Natural Science Foundation of China (No. 21776253 \& 21774077), the National key research and development program of China (No. 2016YFC0401508), the National Basic Research Program of China (No. 2015CB655303) and the Open Research Fund Program of Collaborative Innovation Center of Membrane Separation and Water Treatment of Zhejiang Province.

\section{Notes and references}

1 R. F. Service, Desalination freshens up, Science, 2006, 313, 1088-1090.

2 M. A. Shannon, P. W. Bohn, M. Elimelech, J. G. Georgiadis, B. J. Marinas and A. M. Mayes, Science and technology for water purification in the coming decades, Nature, 2008, 452, 301-310.

3 D. Li and H. T. Wang, Recent developments in reverse osmosis desalination membranes, J. Mater. Chem., 2010, 20, 4551-4566.

$4 \mathrm{M}$. Elimelech and W. A. Phillip, The future of seawater desalination: energy, technology, and the environment, Science, 2011, 333, 712-717.

5 J. Benavente, J. M. Garcia, J. G. de la Campa and J. de Abajo, Determination of some electrical parameters for two novel aliphatic-aromatic polyamide membranes, J. Membr. Sci., 1996, 114, 51-57.

6 J. E. Cadotte, Reverse osmosis membrane, in Application: US, Cont-in-part of US Ser. no. 958593, Midwest Research Institute, USA, 1981, p. 9.

7 R. L. Riley, R. L. Fox, C. R. Lyons, C. E. Milstead, M. W. Seroy and M. Tagami, Spiral-wound poly(ether/amide) thin-film composite membrane systems, Desalination, 1976, 19, 113126.

8 J. E. Cadotte, Reverse osmosis membrane, in Application: US, United States Department of the Interior, USA, 1977, p. 6.

9 K. J. Mysels and W. Wrasidlo, Strength of interfacial polymerization films, Langmuir, 1991, 7, 3052-3053.

10 S. D. Arthur, Preparation and uses of multilayer reverse osmosis membrane of polyamide-urea, in: Application: US, E.I. du Pont de Nemours and Co., USA, 1991, p. 7.

11 L.-F. Liu, S.-C. Yu, Y. Zhou and C.-J. Gao, Study on a novel polyamide-urea reverse osmosis composite membrane (ICIC-MPD), J. Membr. Sci., 2006, 281, 88-94.
12 S. D. Arthur, Reverse-osmosis membranes of polyamideurethanes, in: Application: US, E.I. du Pont de Nemours and Co., USA, 1992, p. 6.

13 M. Liu, S. Yu, J. Tao and C. Gao, Preparation, structure characteristics and separation properties of thin-film composite polyamide-urethane sea water reverse osmosis membrane, J. Membr. Sci., 2008, 325, 947-956.

14 R. Baker, Membrane Technology and Applications, John Wiley \& Sons Ltd, England, 2nd edn, 2004.

15 G.-d. Kang and Y.-m. Cao, Development of antifouling reverse osmosis membranes for water treatment: a review, Water Res., 2012, 46, 584-600.

16 D. Rana and T. Matsuura, Surface modifications for antifouling membranes, Chem. Rev., 2010, 110, 2448-2471.

17 L. Zhao, P. C. Y. Chang, C. Yen and W. S. W. Ho, High-flux and fouling-resistant membranes for brackish water desalination, J. Membr. Sci., 2013, 425-426, 1-10.

18 Y.-N. Kwon and J. O. Leckie, Hypochlorite degradation of crosslinked polyamide membranes: II. Changes in hydrogen bonding behavior and performance, J. Membr. Sci., 2006, 282, 456-464.

19 G.-D. Kang, C.-J. Gao, W.-D. Chen, X.-M. Jie, Y.-M. Cao and Q. Yuan, Study on hypochlorite degradation of aromatic polyamide reverse osmosis membrane, J. Membr. Sci., 2007, 300, 165-171.

20 V. T. Do, C. Y. Tang, M. Reinhard and J. O. Leckie, Degradation of polyamide nanofiltration and reverse osmosis membranes by hypochlorite, Environ. Sci. Technol., 2012, 46, 852-859.

$21 \mathrm{X}$. Song, et al., Ultra-thin, multi-layered polyamide membranes: Synthesis and characterization, J. Membr. Sci., 2017, 540, 10-18.

22 G. D. Kang and Y. M. Cao, Development of antifouling reverse osmosis membranes for water treatment: A review, Water Res., 2012, 46(3), 584-600.

23 N. Fujiwara and H. Matsuyama, Elimination of biological fouling in seawater reverse osmosis desalination plants, Desalination, 2008, 227(1-3), 295-305.

24 A. R. Bartman, et al., Mineral scale monitoring for reverse osmosis desalination via real-time membrane surface image analysis, Desalination, 2011, 273(1), 64-71.

$25 \mathrm{~S}$. T. Weinman and S. M. Husson, Influence of chemical coating combined with nanopatterning on alginate fouling during nanofiltration, J. Membr. Sci., 2016, 513(suppl. C), 146-154.

26 T. Hong Anh Ngo, D. T. Tran and C. Hung Dinh, Surface photochemical graft polymerization of acrylic acid onto polyamide thin film composite membranes, J. Appl. Polym. Sci., 2017, 134(5), DOI: 10.1002/APP.44418(1-9).

27 Y. Zhou, et al., Surface modification of thin film composite polyamide membranes by electrostatic self deposition of polycations for improved fouling resistance, Sep. Purif. Technol., 2009, 66(2), 287-294.

28 N. X. Wang, et al., Ceramic tubular MOF hybrid membrane fabricated through in situ layer-by-layer self-assembly for nanofiltration, AIChE J., 2016, 62(2), 538-546. 
29 L. Wang, et al., Layer-by-layer self-assembly of polycation/GO nanofiltration membrane with enhanced stability and fouling resistance, Sep. Purif. Technol., 2016, 160, 123-131.

30 Q. Chen, et al., High-flux composite hollow fiber nanofiltration membranes fabricated through layer-by-layer deposition of oppositely charged crosslinked polyelectrolytes for dye removal, J. Membr. Sci., 2015, 492, 312-321.

$31 \mathrm{~J}$. Zhao, et al., Fabrication of Ultrathin Membrane via Layerby-Layer Self-assembly Driven by Hydrophobic Interaction Towards High Separation Performance, ACS Appl. Mater. Interfaces, 2013, 5(24), 13275-13283.

32 G. J. Zhang, et al., Self-assembly of polyelectrolyte multilayer pervaporation membranes by a dynamic layer-by-layer technique on a hydrolyzed polyacrylonitrile ultrafiltration membrane, J. Membr. Sci., 2007, 292(1-2), 1-8.

33 N. A. Kotov, S. Magonov and E. Tropsha, Layer-by-layer selfassembly of alumosilicate-polyelectrolyte composites: Mechanism of deposition, crack resistance, and perspectives for novel membrane materials, Chem. Mater., 1998, 10(3), 886-895.

34 H. D. Lin, et al., Layer-by-layer self-assembly of in situ polymerized polypyrrole on sulfonated poly(arylene ether ketone) membrane with extremely low methanol crossover, Int. J. Hydrogen Energy, 2009, 34(24), 9795-9801.

35 G. F. Sun, et al., A layer-by-layer self-assembly approach to developing an aquaporin-embedded mixed matrix membrane, RSC Adv., 2013, 3(2), 473-481.

36 K. L. Cho, et al., Chlorine Resistant Glutaraldehyde Crosslinked Polyelectrolyte Multilayer Membranes for Desalination, Adv. Mater., 2015, 27(17), 2791-2796.

37 N. Li, Z. Liu and S. Xu, Study of antifouling membrane poly(vinyl alcohol) membrane, Membr. Sci. Technol., 1999, 19(3), 1-7.

38 E. Immelman, R. D. Sanderson and E. P. Jacobs, Poly(vinyl alcohol) gel sub-layer for reverse osmosis membranes. II insolubilization by crosslinking with poly(methyl vinyl ether altmaleic anhydride), Desalination, 1993, 94, 37-54.

39 E. Immelman, D. Bezuidenhout and R. D. Sanderson, Poly(vinyl alcohol) gel sub-layers reverse osmosis membranes. III insolubilization by crosslinking with potassium peroxydisulphate, Desalination, 1993, 94, 115132.

40 K. Lang, S. Sourirajan and T. Matsura, A study on the preparation of polyvinyl alcohol thin-film composite membranes and reverse osmosis testing, Desalination, 1996, 104, 185-196.

41 C. W. Michellet, P. John and Z. Andrew, Bench-scale testing of surfactant-modified reverse osmosis/nanofiltration membranes, Desalination, 1998, 115, 15-32.

42 M. Elimelech, X. Zhu and C. Amy etal, Role of membrane surface in colloidal fouling of cellulose acetate and composite aromatic polyamide reverse osmosis membranes, J. Membr. Sci., 1997, 127, 101-109.

$43 \mathrm{~K}$. Ashish, Flux enhancement by hydrophilization of thin film composite RO membrane, J. Membr. Sci., 1996, 114, 39.
44 S. Coker and P. Sehn, Four years field experience with fouling resistant reverse osmosis membranes, Desalination, 2000, 132(1-3), 211-215.

45 S. Wu, J. Xing, C. Zheng, G. Xu, G. Zheng and J. Xu, Plasma modification of aromatic polyamide reverse osmosis composite membrane surface, J. Appl. Polym. Sci., 1997, 64, 1923-1926.

46 C. K. Kim, J. H. Kim, I. J. Roh and J. J. Kim, The changes of membrane performance with polyamide molecular structure in the reverse osmosis process, J. Membr. Sci., 2000, 165, 189-199.

47 D. Mukherjee, A. Kulkarni and N. G. William, Chemical treatment for improved performance of reverse osmosis membranes, Desalination, 1996, 104, 239-249.

48 F. Viatcheslav, G. Jack and B. Sofia, TFC polyamide membranes modified by grafting of hydrophilic polymers: an FT-IR/AFM/TEM study, J. Membr. Sci., 2002, 209, 283-292.

49 Y. Zhou, S. Yu and C. Gao, Surface modification of thin film composite polyamide membranes by electrostatic self deposition of polycations for improved fouling resistance, Sep. Purif. Technol., 2009, 66, 287-294.

$50 \mathrm{~J}$. Xu, X. Feng and C. Gao, Surface modification of thin-filmcomposite polyamide membranes for improved reverse osmosis performance, J. Membr. Sci., 2011, 370, 116-123.

51 C. Wang, G. K. Such, A. Widjays, et al., Click poly(ethylene glycol) multilayers on RO membranes: Fouling reduction and membrane characterization, J. Membr. Sci., 2012, 409410, 9-15.

52 G. J. Zhang, et al., Self-assembly of polyelectrolyte multilayer pervaporation membranes by a dynamic layer-by-layer technique on a hydrolyzed polyacrylonitrile ultrafiltration membrane, J. Membr. Sci., 2007, 292(1-2), 1-8.

53 N. A. Kotov, S. Magonov and E. Tropsha, Layer-by-layer selfassembly of alumosilicate-polyelectrolyte composites: Mechanism of deposition, crack resistance, and perspectives for novel membrane materials, Chem. Mater., 1998, 10(3), 886-895.

54 H. D. Lin, et al., Layer-by-layer self-assembly of in situ polymerized polypyrrole on sulfonated poly(arylene ether ketone) membrane with extremely low methanol crossover, Int. J. Hydrogen Energy, 2009, 34(24), 9795-9801.

55 I. Sawada, R. Fachrul, T. Ito, et al., Development of a hydrophilic polymer membrane containing silver nanoparticles with both organic antifouling and antibacterial properties, J. Membr. Sci., 2012, 387, 1-6.

56 S. H. Kim, S. Y. Kwak, B. H. Sohn, et al., Design of TiO2 nanoparticle self-assembled aromatic polyamide thin-filmcomposite (TFC) membrane as an approach to solve biofouling problem, J. Membr. Sci., 2003, 211(1), 157-165.

57 L. Malaeb and G. M. Ayoub, Reverse osmosis technology for water treatment: State of the art review, Desalination, 2011, 267(1), 1-8.

$58 \mathrm{X}$. Song, et al., Ultra-thin, multi-layered polyamide membranes: Synthesis and characterization, J. Membr. Sci., 2017, 540, 10-18. 
59 G. D. Kang and Y. M. Cao, Development of antifouling reverse osmosis membranes for water treatment: A review, Water Res., 2012, 46(3), 584-600.

60 X. Zhu, R. Bai, K. H. Wee, et al., Membrane surfaces immobilized with ionic or reduced silver and their antibiofouling performances, J. Membr. Sci., 2010, 363(1-2), 278-286.

61 S. H. Kim, S. Y. Kwak, B. H. Sohn, et al., Design of TiO2 nanoparticle self-assembled aromatic polyamide thin-filmcomposite (TFC) membrane as an approach to solve biofouling problem, J. Membr. Sci., 2003, 211(1), 157-165.

62 T. Shintani, H. Matsuyama and N. Kurata, Effect of heat treatment on performance of chlorine-resistant polyamide reverse osmosis membranes, Desalination, 2009, 247(1-3), 370-377.

63 S. T. Weinman and S. M. Husson, Influence of chemical coating combined with nanopatterning on alginate fouling during nanofiltration, J. Membr. Sci., 2016, 513(suppl. C), 146-154.

64 Y. Zhou, et al., Surface modification of thin film composite polyamide membranes by electrostatic self deposition of polycations for improved fouling resistance, Sep. Purif. Technol., 2009, 66(2), 287-294.

65 T. Shintani, H. Matsuyama and N. Kurata, Effect of heat treatment on performance of chlorine-resistant polyamide reverse osmosis membranes, Desalination, 2009, 247(1-3), 370-377.

66 S. Y. Lee, H. J. Kim, R. Patel, et al., Silver nanoparticles immobilized on thin film composite polyamide membrane: characterization, nanofiltration, antifouling properties, Polym. Adv. Technol., 2007, 18(7), 562-568.

67 S. H. Kim, S. Y. Kwak, B. H. Sohn, et al., Design of $\mathrm{TiO}_{2}$ nanoparticle self-assembled aromatic polyamide thin-filmcomposite (TFC) membrane as an approach to solve biofouling problem, J. Membr. Sci., 2003, 211(1), 157-165.

68 C. Dong, Z. Wang, J. Wu, et al., A green strategy to immobilize silver nanoparticles onto reverse osmosis membrane for enhanced anti-biofouling property, Desalination, 2017, 401, 32-41.

69 S. H. Sonawane, A. Terrien, A. S. Figueiredo, et al., The role of silver nanoparticles on mixed matrix $\mathrm{Ag} /$ cellulose acetate asymmetric membranes, Polym. Compos., 2017, 38(1), 32-39.

70 W. L. Chou, D. G. Yu and M. C. Yang, The preparation and characterization of silver-loading cellulose acetate hollow fiber membrane for water treatment, Polym. Adv. Technol., 2010, 16(8), 600-607.

71 M. Ben-Sasson, X. Lu, E. Bar-Zeev, et al., In situ formation of silver nanoparticles on thin-film composite reverse osmosis membranes for biofouling mitigation, Water Res., 2014, 62, 260-270.

72 Z. Yang, Y. Wu, J. Wang, et al., In situ reduction of silver by polydopamine: A novel antimicrobial modification of a thin-film composite polyamide membrane, Environ. Sci. Technol., 2016, 50(17), 9543-9550.

73 X. Liu, S. Qi, Y. Li, et al., Synthesis and characterization of novel antibacterial silver nanocomposite nanofiltration and forward osmosis membranes based on layer-by-layer assembly, Water Res., 2013, 47(9), 3081-3092.

74 S. Liu, F. Fang, J. Wu, et al., The anti-biofouling properties of thin-film composite nanofiltration membranes grafted with biogenic silver nanoparticles, Desalination, 2015, 375, 121128.

$75 \mathrm{~J}$. Wu, C. Yu and Q. Li, Novel regenerable antimicrobial nanocomposite membranes: Effect of silver loading and valence state, J. Membr. Sci., 2017, 531, 68-76.

76 Z. Yang, Y. Wu, H. Guo, et al., A novel thin-film nanotemplated composite membrane with in situ silver nanoparticles loading: separation performance enhancement and implications, J. Membr. Sci., 2017, 544, 351-358.

77 T. Kawaguchi and H. Tamura, Chorine-resistance membrane for reverse osmosis: 1 Correlation between chemical structures and chlorine resistance of polyamides, J. Appl. Polym. Sci., 1984, 29, 3359-3367.

78 J. Koo, R. J. Peterson and J. E. Cadotte, ESCA characterization of chlorine damaged polyamide reverse osmosis membrane, ACS Polymer Preprints, Division of Polymer Chemistry, 1986, 27, 391-392.

79 K. Nita, Y. Matsui, et al., in ICOM'90, Chicago, 1990, p. 1055. $80 \mathrm{X}$. Zhao, Y. He, Z. Wu and Z. Cai, Chlorine-resistant composite reverse osmosis membrane, $\mathrm{CN}$ Pat. 101130155A, 2008.

81 A. P. Murphy, B. Murugaverl and R. L. Riley, Chlorine resistant polyamides and membranes made from the same, USPTO Application \#: 20080277333, 2008.

82 S. Yu, M. Liu, Z. Lü, et al., Aromatic-cycloaliphatic thin-film composite membrane with improved chlorine resistance prepared from m-phenylenediamine-4-methyl and cyclohexane-1,3,5-tricarbonyl chloride, J. Membr. Sci., 2009, 344, 155-164.

83 S. Takuji, M. Hideto and K. Naoki, Development of a chlorine-resistant polyamide reverse osmosis membrane, Desalination, 2007, 207, 340-348.

84 S. Takuji, M. Hideto and K. Naoki, Effect of heat treatment on performance of chlorine-resistant polyamide reverse osmosis membranes, Desalination, 2009, 247, 370-377.

85 L.-F. Liu, D.-Z. XU, H.-L. Chen and C.-J. Gao, A novel polyamide-urea-imide composite reverse osmosis membrane prepared via two-step interfacial polymerization, Journal of Chemistry and Engineering, 2012, 63, 1913-1921.

86 G.-D. Kang, C.-J. Gao, W.-D. Chen, et al., Study on hypochlorite degradation of aromatic polyamide reverse osmosis membrane, J. Membr. Sci., 2007, 300, 165-171.

87 Y. K. Kim, S. Y. Lee, D. H. Kim, et al., Preparation and characterization of the thermally crosslinked chlorine resistant thin film composite polyamide membrane for reverse osmosis, Desalination, 2010, 250, 865-867.

88 X. Wei, Z. Wang, J. Chen, et al., A novel method of surface modification on thin-film-composite reverse osmosis membrane by grafting hydantoin derivative, J. Membr. Sci., 2010, 346, 152-162. 
89 J. Xu, Z. Wang, L. Yu, J. Wang, et al., A novel reverse osmosis membrane with regenerable chlorine resistant properties, $J$. Membr. Sci., 2013, 435, 80-91.

90 Y.-H. La, J. Diep, R. Al-Rasheed, et al., Enhanced desalination performance of polyamide bi-layer membranes prepared by sequential interfacial polymerization, J. Membr. Sci., 2013, 437, 33-39.

91 L. Liu, S. Yu, Y. Zhou, K. Jin and C. Gao, Preparation of 5choroformyloxyisophthaloyl chloride, Fine Chem., 2005, 22, 227-300.

92 P.-Q. Mao, L.-F. Liu, D.-Z. Xu and C.-J. Gao, Synthesis of $N, N$ 'dimethyl-1,3-benzenediamine by reduction method with NaBH4 and I2, Chem. J. Chin. Univ., 2011, 32, 2558-2561.

93 L.-F. Liu, Z.-B. Cai, J.-N. Shen, L.-X. Wu, E. M. V. Hoek and C.-J. Gao, Fabrication and characterization of a novel poly (amide-urethane@imide) TFC reverse osmosis membrane with chlorine-tolerant property, J. Membr. Sci., 2014, 469, 397-409.

94 N. P. Soice, A. C. Maladono, D. Y. Takigawa, A. D. Norman, W. B. Krantz and A. R. Greenberg, Oxidative degradation of polyamide reverse osmosis membranes: studies of molecular model compounds and selected membranes, $J$. Appl. Polym. Sci., 2003, 90, 1173-1184.

95 Y.-N. Kwon, Change of surface properties and performance due to chlorination of crosslinked polyamide membranes, PhD Dissertation, Stanford University, 2005.

96 Z. Liu, L. Qi, X. An, C. Liu and Y. Hu, Surface Engineering of Thin Film Composite Polyamide Membranes with Silver Nanoparticles through Layer-by-Layer Interfacial Polymerization for Antibacterial Properties, ACS Appl. Mater. Interfaces, 2017, 9, 40987-40997.

97 J. Duan, E. Litwiller and I. Pinnau, Preparation and water desalination properties of POSS-polyamide nanocomposite reverse osmosis membranes, J. Membr. Sci., 2015, 473, 157-164.

98 O. Habimana, A. J. C. Semião and E. Casey, The role of cellsurface interactions in bacterial initial adhesion and consequent biofilm formation on nanofiltration/reverse osmosis membranes, J. Membr. Sci., 2014, 454, 82-96.

99 J. Zhu, J. Hou, Y. Zhang, M. Tian, T. He, J. Liu and V. Chen, Polymeric antimicrobial membranes enabled by nanomaterials for water treatment, J. Membr. Sci., 2018, 550, 173-197. 